\section{PERMISO PARA JARANEAR}

\author{
¿DE QUE SE TRATA TODO ESTO?
}

V iernes 13 de marzo, el escritor Alfredo Bryce Echenique (Lima, 1939) absorbe unas gotas de pisco mosto verde de una copita. Luego, llenaría una más grande con vino tinto. Cierra los ojos. Parpadea varias veces. Se acomoda sus característicos anteojos. Se estremece al escuchar Luis Enrique Enrique, el plabeyo de Felipe Pinglo. Cruza las piernas. Aplaude. Se divierte. Se enternece por los valses antiguos en La Catedral del Criollismo, o en la salita de reuniones del guitarrista criollo Wendor Salgado Bedoya (Barranca, 1941). Podría decirse que es una de las escenas de sus últimas antimemorias mientras muchachos de su generación

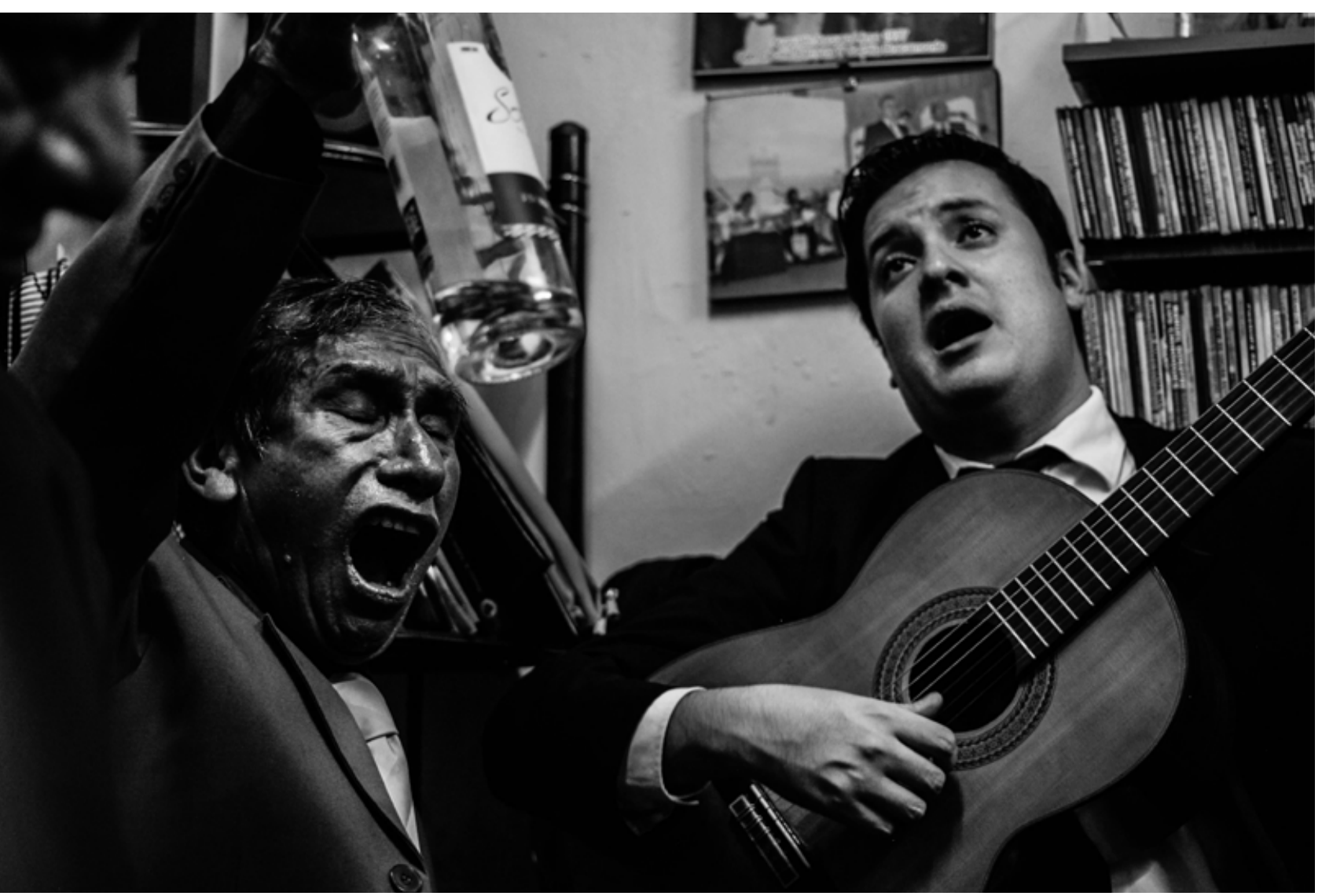

Lalo Llanos y Bruno Lara en La Catedral del Criollismo, 2018. se asombran de verlo frente al dueño de casa. Susurran. Se codean. Ríen.

Nicomedes Santa Cruz dedicó una décima a Alfredo en 1987 donde decía que era blanco con alma de zambo, un limeño mazamorrero de espíritu aventurero, que había nacido para la novela. Así, lo encontré bebiendo shots de pisco y escuchando, atentamente, a una comitiva de criollos piuranos que llegaron a la cuadra 11 de Pariacoto en Breña para disfrutar -quién hubiera sabido- del último viernes de jarana en La Catedral antes que se decretara cuarentena en el Perú por la pandemia de la COVID-19 en el 2020.

Esta última jarana fue significativa porque los viejos ya no se abrazarían ni escucharían a los suyos sin que haya tantos metros de distancia de por medio. O les costara aprender a usar las plataformas de videollamadas que tanto están de moda ahora. Los criollos están sumergidos en una etapa que llamo el silencio de la resistencia. En fin, Bryce Echenique también bebía el mejor vino de la mesa. Aplaudía. Se divertía con la literatura que pasaba frente a sus ojos. No obstante, en 2019 se despedía después de una carrera de más de 50 años, en la que produjo una treintena de títulos. Eso hacía que me preguntara: ¿Cómo quiero envejecer? ¿Al lado de quiénes?

De vuelta al barrio, la música criolla me ha permitido conocer mi ciudad, una que para muchos de los limeños a veces permanece invisible. La gente no tiene por qué desconocer su historia. La música criolla es nuestra música subterránea que está por diversos sitios. Es una historia que no, necesariamente, ha sido de éxitos. El investigador Daniel Mattews - parroquiano de La Catedral- decía que la ciudad tiene que ver con cómo hablamos de ella y nos sentimos en ella. Jamás olvidaré cuando fuimos un grupo de "viejos prematuros" y el señor Antonio Graña al Pipo Comena en las primeras cuadras del Jr. Chamaya en Chacra Colorada para seguir entonando valses. Saque la cámara. Y venían las botellas de cerveza chispas y alegría. Graña solo atinó a decirles: "Él no es el fotógrafo del criollismo. Él es el criollo de la fotografía".
En casa, al encender la radio, siempre me llamó la atención ese ritmo alegre, el repiquetear de los cajones, las palabras de apoyo, los chistes colorados y la salud etílica que iba y venía junto a esa actitud, ese sabor especial, que entregaban sus compositores e intérpretes. Para mí, La Catedral y la venia del maestro Wendor -junto al apoyo constante de Elías Arana y Ricardo Martínez- fueron una puerta abierta al universo criollo de Lima.

Desde el 11 de abril de 2014, una semana después de la muerte de Óscar Avilés, asistí religiosamente todos los viernes a este espacio que respira respeto por la interpretación, difusión e investigación de canciones poco conocidas de nuestra música criolla. Siempre he dicho que esta búsqueda por saber lo que a uno lo hace criollo me llevó a romper prejuicios, como aquel que asocia lo criollo con la viveza, cuando en realidad el criollismo apunta a cuidar la amistad. Una amistad que se macera entre las cuerdas de una guitarra.

Hay una frase que deja perplejo: "Que mueran los viejos para que no se sepa la verdad". Yo pienso todo lo contrario para contar y retratar sus historias. $Y$ es que, sin ellos, que son nuestras primeras fuentes, ¿cómo vamos a saber lo que pasó? ¿por qué no informar al mundo las ganas que ponen estos señores en cada interpretación? ¿por qué no se les presta más atención de lo debido? ¿Por qué no se conocen más historias al respecto? ¿Por qué siempre seguimos escuchando lo mismo en la mayoría de las radios? ¿Por qué varios de mis colegas no se atreven a poner un pie en un centro musical o en los barrios donde el criollismo, no tan conocido por los grandes medios tradicionales, suena más allá de los 28 de julio y 31 de octubre? ¿O por qué no quieren escuchar?

Ellos guardan datos y uno, como periodista, quiere que lo cuenten para entender cómo crean ese sonido, qué ha pasado en su vida para que tomen la decisión de ir cada viernes. El criollismo no desaparecerá mientras uno lo celebre, lo recuerde y esté atento a lo que sucede con otros espacios. De este modo, hemos 
compartido momentos en distintas peñas del Rímac, Breña y Lince; junto a los más jóvenes en Barrios Altos y La Victoria por mencionar algunos espacios. Los señores siguen mi trabajo no solo por lo que les cuento, sino porque también están atentos a las publicaciones vía internet. Todo este universo es noticia en desarrollo por las miradas, las acciones, los dichos de sus rockstars sub de sol a sol. De lunes a lunes. De ahí que siempre estaré agradecido por haber conocido los hechos que construyeron el criollismo en Lima durante la segunda década del siglo XX.

Javier Darío Restrepo, maestro colombiano de este oficio, experto en ética periodística decía en La vejez en las noticias (2017) que "toda

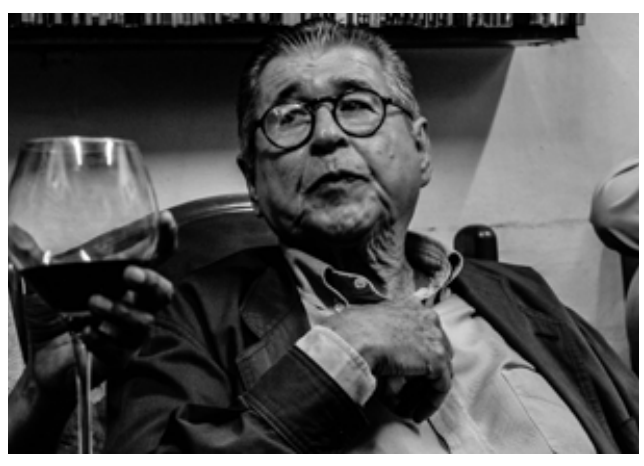

Las hermanas López siempre me recibirán con calurosos abrazos y besos, muy atentas en que registrara las noches en el pasadizo más agitado de la cuadra seis del jirón Pedro Conde en Lince. Desde el mejor ángulo en el espacio chico, pero de corazón grande, se escuchan las risas de sus comensales o la algarabía que sus músicos originan de canción tras canción.

Alfredo Bryce Echenique en La Catedral, 2020).

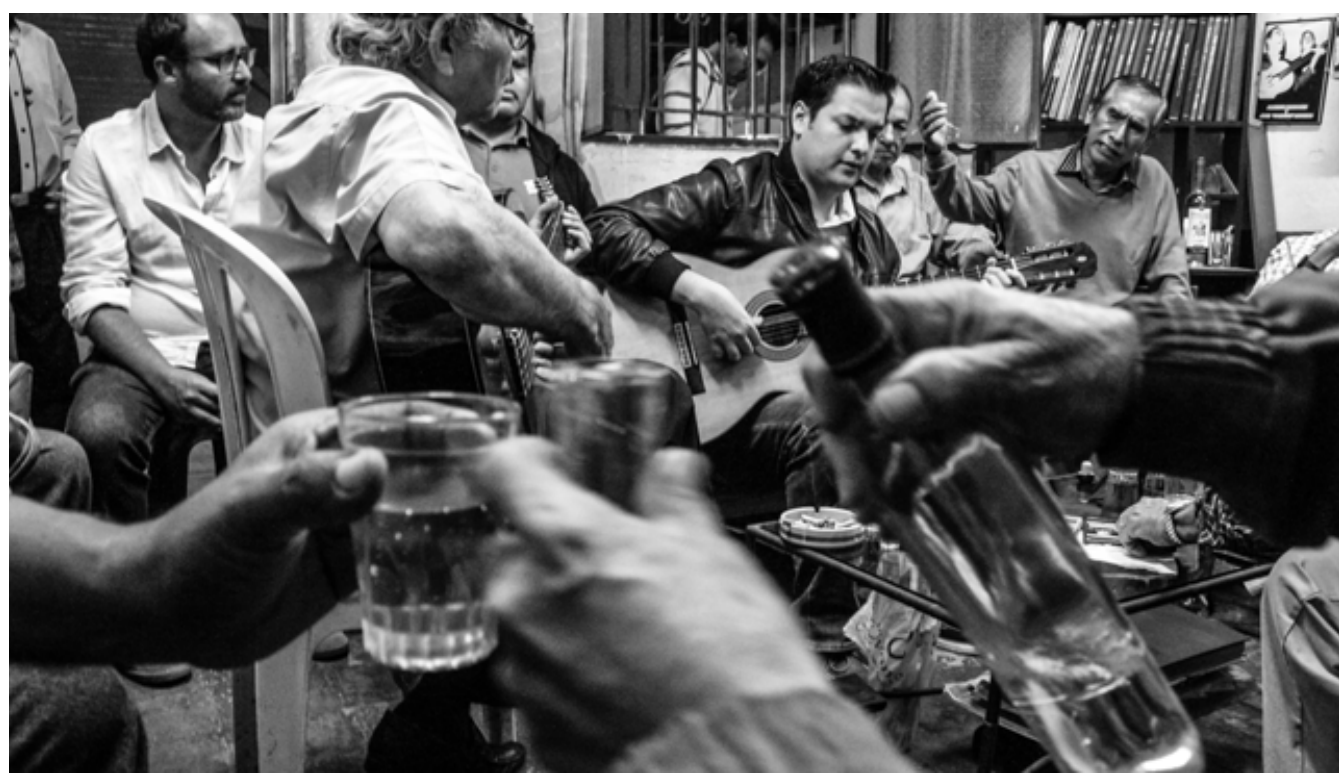

persona vieja siembra semillas de inmortalidad cada vez que activa su voluntad de ser bien recordada". Para mí, los criollos mayores, en sus jaranas, siembran los recuerdos que les . Ellos se vuelven inmortales porque viven, fomentan y difunden todo de sí en cada olvido, otros no se dejan sorprender. Hay mucho corazón. Hay mucha responsabilidad. Es como el hambre. Un ejercicio. Es una lucha interna contra el olvido. Es la naturaleza del envejecer. Pero, surgen preguntas: ¿Qué pasaría si olvido? Como serían mis recuerdos si ya no estuviera que se pierde a alguien? No solo soy yo, somos un manchón de gente. Alguien se olvida la letra pero todos evitamos que caiga. Recordar para vivir. Vivir para recordar.

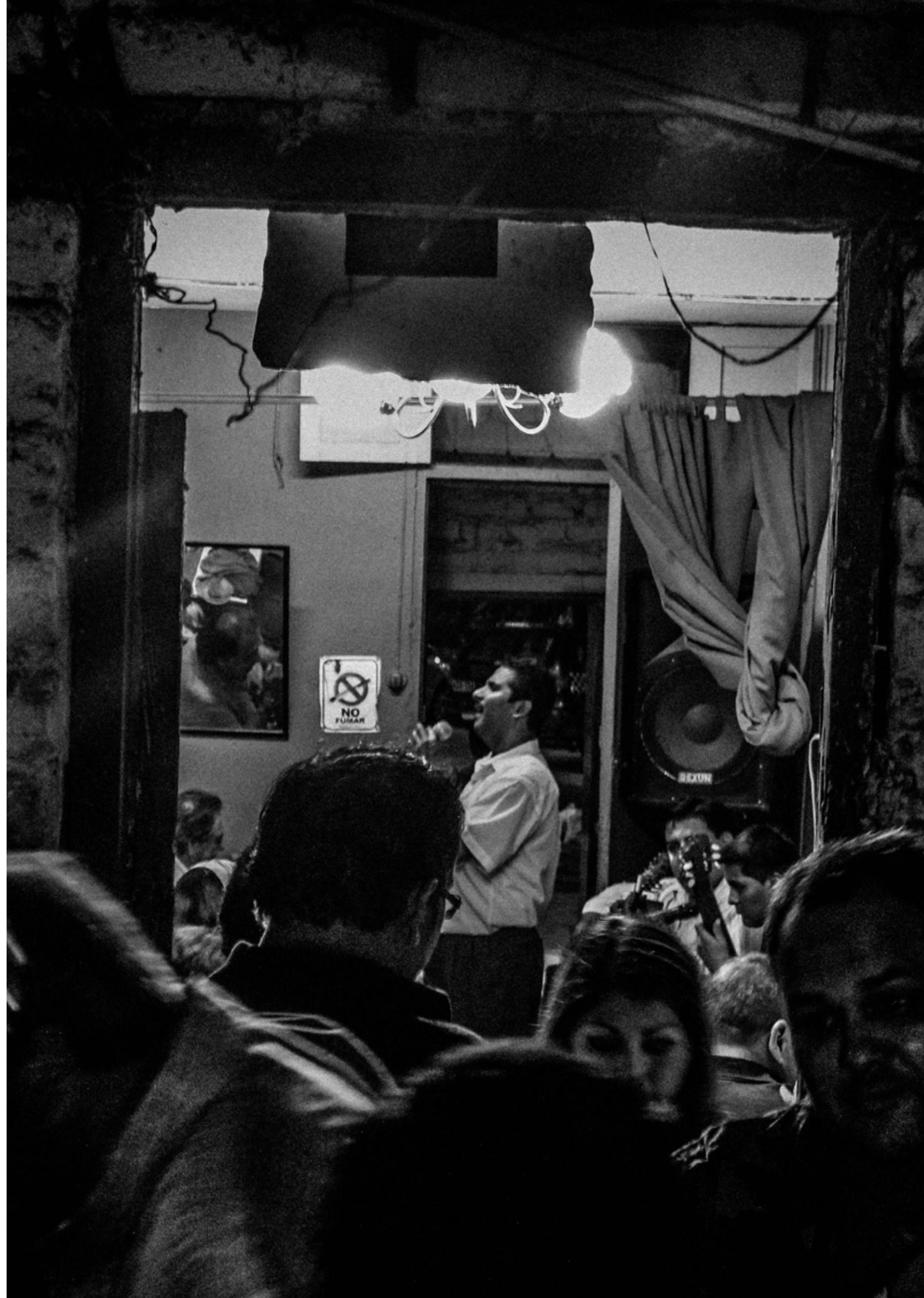


Jamás olvidaré las palabras de Antonio Graña en una de sus mesas tras preguntarle sobre qué es "ser criollo". Respondió lo siguiente: Es haber sentido lo que tú estás cantando. Realmente que salga de tu alma... que no digas que sale de tu alma, sino que verdaderamente salga de tu alma... Y para que salga de tu alma tienes que haberlo vivido. Tienes que sentirlo. Tienes que ser crio 作 a todas las horas. Hasta para dormir.

Un claro ejemplo de esta sentencia es Lalo Llanos, de corta estatura, pero de una gran y dulce voz, cierra sus ojos negros cuando Ingresa en un trance. Una catarsis en cada estrofa. Cuando canta, parece que fuera un exorcismo. Están saliendo todos los demonios. "¡Los demonios de los andes!", le gritan. Ese es su estilo para combatir la odisea que representa la indiferencia. Al levantar sus manos después de cada línea, al suavizar el final de los versos, o contando la historia de un personaje, coloca en un sitial esta expresión musical. ¿Y si alguien no entiende el mensaje? "Yo reacciono mal. A veces, los criollos nos emborrachamos por esas injusticias, por nuestra música", ríe.

A veces, siente cierta desazón cuando en la TV siguen cantando lo mismo. "La música criolla no solo es eso. Va más allá". Para Lalo, es más que una canción. Ha memorizado cientos de canciones, pero icómo es tan fácil? "Yo ni sé. Lo juro. Como estoy con la edad, digo en mi casa: ¡Voy a cocinar! Estoy cocinando. Voy a la refrigeradora y digo: ¿Para qué he venido? No me acuerdo. Pero, ¿cómo es que me acuerdo del repertorio?"

$$
\text { *** }
$$

Yo no niego que entre copas y guitarras he vivido muchas horas de placer. Estos retratos también muestran compañía, soledad, esperanza, inquietud, sueños y recuerdos, sentimientos que dan vida a la música criolla.

Recuerdo la voz, la soltura y la alegría de la compositora Ana Renner retumbando todos los miércoles desde que empecé a ir, en 2014, al Centro Social Deportivo J.R Vallejos Bozzo de Lince, así como las palabras de aliento que brin- esperanza en que el criollismo tendrá quien le cante, a mucha honra, cuando ya no esté.

Jamás olvidaré a Adolfo Zelada y su interpretación de Mi primera elegía de Serafin Quinteras en el Salón Dorado del Teatro Municipal en julio de 2018. Zelada nos dejó a los 96 años, de los cuales 79 los vivió en la espies muy humilde. Que, así como habla, se toca. Tengo un gran sentido de la ubicación de las notas y mi cuerpo emana ese tipo de alegría cuando tomo un instrumento. Las brindo con todo el corazón y el cerebro".

Los dos músicos ya no están, pero quiero creer que vivieron agradecidos y lejos de la tristeza que el tiempo imprime. Porque ellos siempre buscaron dar un poquito de charla, de por qué se toca así, por qué hay determinado instrumento, a qué año se remonta, o a quién está dedicada. Entonces, al abordar la música pretendemos darle voz a las personas que están detrás de cada melodía. Y decir: Aquí están, existen, con sus propios gestos. Con sus propias formas de convivencia, con sus propios respetos que merecen ser atendidos.

***

La Catedral no es una iglesia, pero muchos de sus asistentes mencionan -a sus esposas, a sus amigos, a sus allegados- que van a misa todos los viernes. Este espacio los confiesa desde lo más íntimo. Wendor es parte de la vivencia de la música criolla. La música criolla es parte de la vivencia de Wendor. Sin familia y sin controles, se dedica a la jarana como una manera de exorcizar la soledad y de reunirse con los poetas de la calle, quienes lo buscan para hablar de criollismo, convirtiéndose en el oráculo de Breña. Wendor es un líder musical o un quardián de la tradición, como dicen los antropólogos, porque es el punto medio entre los saberes que se transmiten y el grupo que los reproduce. Señores y viejos prematuros lo erigieron como guardián.

"El repertorio criollo es muy extenso. Es tan extenso que no alcanzaríamos a saber todo. Nadie sabe todo de la música criolla, porque

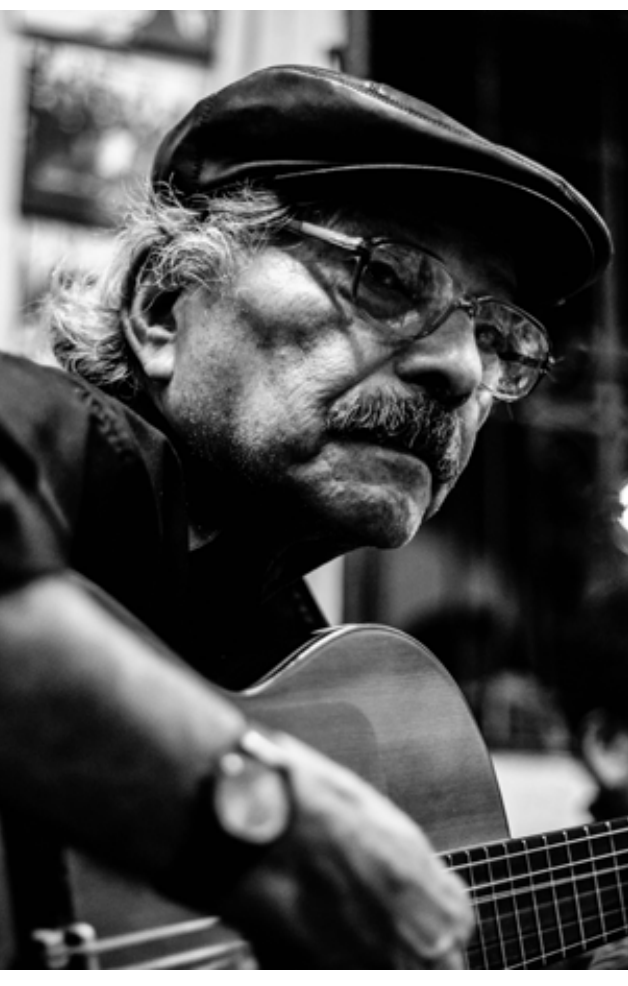

Wendor Salgado Bedoya, 2015.

hay por todos lados: valses nuevos, valses antiguos. Y uno encuentra valses antiguos de Piura, de Lambayeque, de Chincha, de Arequipa. Esta parte del folclore nacional siempre ha estado presente, solo que nunca ha tenido la valoración que debió tener", palabras finales de Wendor Salgado para dar inicio a la celebración por el undécimo aniversario de La Catedral de Criollismo, en el Centro Social Cultural Musica Breña, en el 2015

No todos los lugares son tan cerrados. S es que tiene la voluntad, oiga. Para Wendor lo importante es el gusto por la música criolla, la disposición y la constancia en la práctica: "Tiene que gustarle mucho, tiene que gustarle para que esté ahí, atrás de los que saben. Para escuchar, para comentar y, de vez en cuando, meter su cuchara".

Disfrutemos entonces de esos valses que dan sed. La música criolla es magia que moviliza, nutre, comunica, sensibiliza e integra. Lo único que pido, cuando la pandemia termine, es que mi sangre se sancoche en el corazón de la

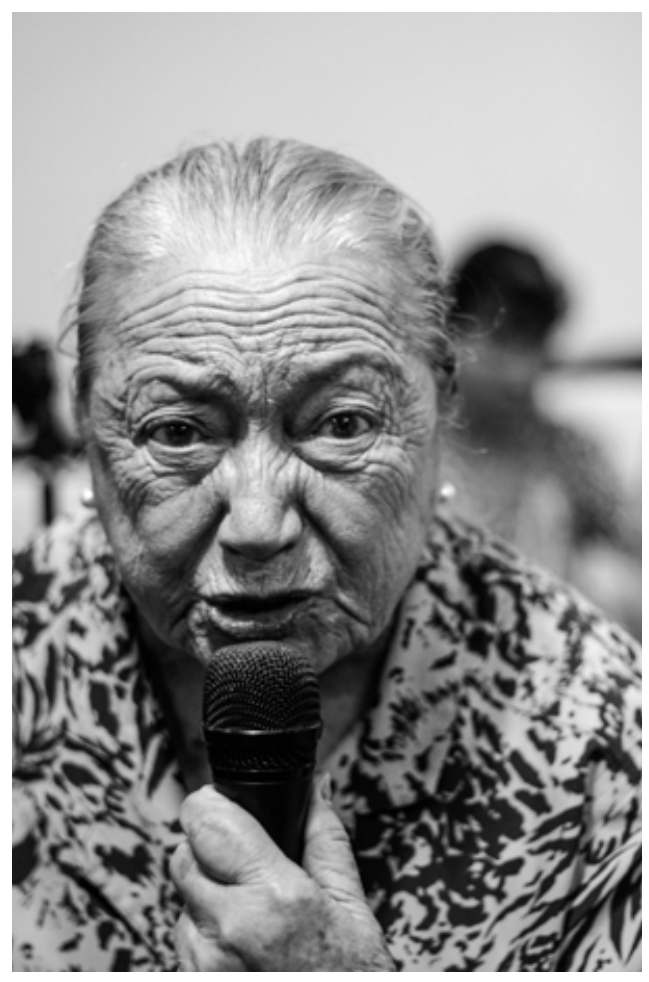

Ana Renner, 2015

jarana y que después de todo lo cantado llegue Carlos Leturia con un vaso lleno de cerveza y, acompañado de su voz susurrante, diga: ¿De qué se trata todo esto? $\bullet$

EN LA TARDE DEL VIERNES 21 DE ABRIL, UN DÍA ANTES QUE KYLE DILLINGHAM, VIOLINISTA ESTADOUNIDENSE, VIAJARA DE REGRESO A OKLAHOMA, IMPROVISÓ UNOS SOLOS EN MEDIO DE LA INTERPRETACIÓN DE GABRIEL DURAND DEL DE LANTINTUARTACION DE GABREL DURAND DEL JUNTO A LA GUITARRA DE WENDOR SALGADO EN "LA CATEDRAL DE CRIOLLISMO". ESCANEA EL CÓDIGO QR.

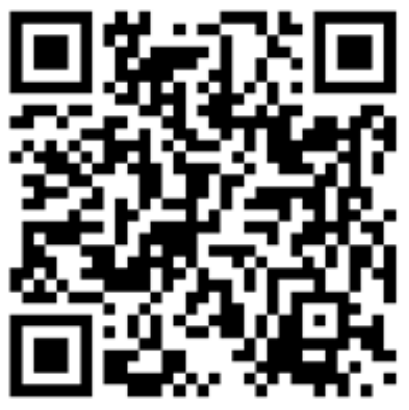




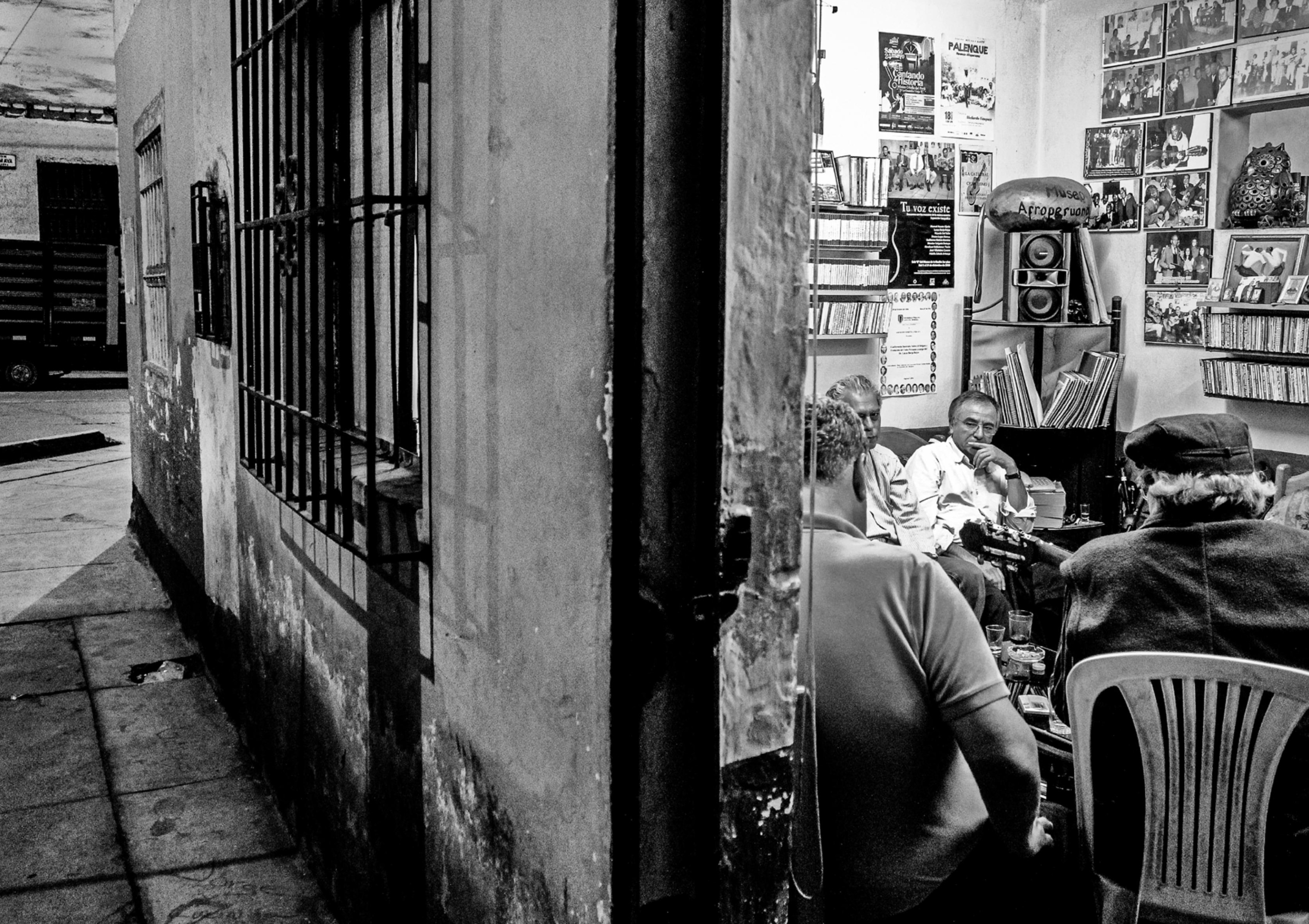

